\section{Estigma e resistência entre travestis e mulheres transexuais em Salvador, Bahia, Brasil}

\author{
Stigma and resistance among travestis and \\ transsexual women in Salvador, Bahia State, \\ Brazil
}

\section{Estigma y resistencia entre travestis y mujeres transexuales en Salvador, Bahía, Brasil}

Laio Magno 1,2

Inês Dourado 2

Luis Augusto Vasconcelos da Silva 2,3

\section{Resumo}

Trata-se de um estudo qualitativo, com base na análise de narrativas produzidas por travestis e mulheres transexuais em Salvador, Bahia, Brasil, com o objetivo de analisar suas experiências de estigmatização, descrevendo acontecimentos, atores e contextos que marcam as suas trajetórias de vida, e também compreender a relação entre o estigma e suas performances femininas. As narrativas são provenientes de 19 entrevistas em profundidade realizadas ao longo de um inquérito epidemiológico. Foram orientadas por um roteiro prévio que explorou a produção de narrativas sobre as experiências e modos de vida das travestis e mulheres transexuais na cidade de Salvador. As histórias de vida que emergiram do campo foram transcritas e analisadas sob uma perspectiva teórico-narrativa. Observou-se que muitas travestis e mulheres transexuais apresentaram em suas narrativas a descrição de uma performance de gênero "afeminada", que é identificada desde à infância por membros da família e da comunidade. Essa performance é apresentada como uma insubordinação ao poder estabelecido pelo sistema jurídico da sociedade heteronormativa. O processo de estigmatização começa a operar quando as expectativas sociais sobre a coerência entre "sexo biológico" e "performance de gênero" são frustradas nas interações sociais, submetendo as pessoas à discriminação e violência. Desse modo, o processo de estigmatização é operado por meio do poder exercido pelas leis da heterossexualidade compulsória sobre os corpos. Entretanto, durante as trajetórias de vida das travestis e mulheres transexuais, estratégias de resistência contra o estigma são produzidas com o potencial de transformação dos quadros estabelecidos.

Exposição à Violência; Estigma Social; Identidade de Gênero; Pessoas Transgênero

\author{
Correspondência \\ L. Magno \\ Departamento de Ciências da Vida, Universidade do Estado da \\ Bahia. \\ Rua Silveira Martins 2555, Salvador, BA 41150-000, Brasil. \\ laiomagnoss@gmail.com \\ 1 Departamento de Ciências da Vida, Universidade do Estado da \\ Bahia, Salvador, Brasil. \\ 2 Instituto de Saúde Coletiva, Universidade Federal da Bahia, \\ Salvador, Brasil. \\ 3 Instituto de Humanidades, Artes er Ciências Professor Milton \\ Santos, Universidade Federal da Bahia, Salvador, Brasil.
}




\section{Introdução}

As pessoas trans, ao transgredirem a matriz heterossexual compulsória, pautada pela coerência entre sexo, gênero e desejo, são consideradas "seres abjetos" 1 e, consequentemente, estigmatizadas em sociedades heteronormativas - aquelas que normatizam a heterossexualidade como um dispositivo natural e compulsório 2. No Brasil, faz-se presente uma discussão sobre a fluidez e instabilidade das categorias identitárias travesti e transexual. Lionço ${ }^{3}$ (p. 54) argumenta que as travestis e transexuais "se constituem subjetivamente como indivíduos pertencentes a um gênero que não corresponde linearmente ao sexo de nascimento". Porém, as travestis sustentam uma "ambiguidade ou duplicidade sexual na própria afirmação identitária" 3 (p. 54). Por outro lado, as fronteiras entre travestis e transexuais encontram-se borradas no cotidiano, podendo haver um "trânsito" entre tais identidades; portanto não são fixas ou isoladas, mas posições sempre disputadas, negociadas, em constante interação e movimento 4,5.

Destaca-se também que, apesar de a literatura internacional se referir à categoria "mulheres transgêneras" (transgender women), no contexto brasileiro as categorias travestis e mulheres transexuais continuam a ser usadas, ainda que ocorram tensões e posicionamentos diversos, inclusive com a participação dos discursos biomédicos. Vale a pena lembrar que a identidade transexual como uma "categoria psiquiátrica" foi utilizada, inicialmente, para viabilizar (e restringir) o processo de modificação corporal no Sistema Único de Saúde (SUS) 3.

A tentativa de controle normativo das identidades trans se dá por processos de estigmatização que vão desde o nível estrutural até as interações sociais cotidianas ${ }^{6}$. A psiquiatria, por exemplo, tem patologizado as performances que fogem ao padrão binário heteronormativo com o rótulo de disforia de gênero 7. No âmbito das relações sociais, a discriminação, violência e exclusão são relatadas por vários estudos tanto no Brasil 8,9,10,11,12 quanto em outros países do mundo 13,14,15 como parte do cotidiano de muitas mulheres transgêneras. Estudos apontam que elas são mais discriminadas do que os gays ou homossexuais 16 , sendo até mesmo discriminadas dentro da comunidade gay 17 . As trajetórias de muitas delas são marcadas por violações aos direitos humanos, com histórias de encarceramento policial por conta da identidade de gênero 18,19, criminalização 20 e violência 21 . Nos serviços de saúde, muitas também enfrentam discriminação e possuem pouco acesso 21,22,23,24. Além disso, enfrentam a ausência de acesso ao uso adequado de hormônios 13,20 e de procedimentos cirúrgicos para modificação corporal 25. Outra questão importante é a dificuldade em realizar a readequação do nome de registro em consonância com sua identidade de gênero 13 .

Nesse contexto, a discussão em torno do conceito de estigma se torna imperiosa, pois o processo de estigmatização destaca um traço específico do indivíduo. No caso das mulheres transgêneras, esse traço é a identidade de gênero, o que impossibilita que outros atributos tenham atenção, imputandolhes descrédito 26 e discriminação, que, por sua vez, produz desfechos negativos de saúde. O estigma e a discriminação, por exemplo, estão geralmente associados com a exclusão social, a baixa escolaridade $15,27,28$ e com as barreiras no acesso ao mercado de trabalho 20,27,28, podendo influenciar a entrada dessas pessoas no mercado sexual 20,27,28 e a adoção de comportamentos de risco para doenças e agravos, como o uso de substâncias injetáveis sem orientações médicas e o sexo anal desprotegido com parceiros sexuais 29; também com desfechos psiquiátricos (como ansiedade e depressão) 20,30 e uso de substâncias psicoativas 30,31,32.

Nesse sentido, apesar de muitos estudos destacarem o estigma e seus efeitos na população de mulheres transgêneras 6 , pouco se tem analisado acerca dos mecanismos de poder e resistência presentes na experiência de estigmatização de travestis e mulheres transexuais em sociedades hegemonicamente heteronormativas, como a brasileira. Este artigo, portanto, pretende analisar narrativas sobre experiências de estigmatização entre travestis e mulheres transexuais em Salvador, Bahia, Brasil, descrevendo acontecimentos, atores, contextos e resistência que marcam as suas trajetórias de vida, e também compreender a relação entre o estigma e suas performances femininas.

\section{Metodologia}

O presente artigo é resultado de um estudo etnoepidemilógico 33 com travestis e mulheres transexuais, denominado estudo PopTrans, realizado entre 2014 e 2016. Os critérios de inclusão no estudo 
foram: identificar-se como travesti ou como mulher transexual, idade igual ou superior a 15 anos e morar em Salvador ou região metropolitana no período do estudo. Estas identidades "travesti" e "mulher transexual" foram autorreferidas durante o desenvolvimento da pesquisa. Detalhes sobre a metodologia do estudo podem ser encontrados em Dourado et al. 5 .

Durante o inquérito, e após a aplicação dos questionários quantitativos, os/as entrevistadores/ as de campo, juntamente com a equipe de coordenação do estudo, indicavam algumas travestis e mulheres transexuais e as convidavam para as entrevistas em profundidade com base na diversidade sociodemográfica e das experiências dessas participantes, buscando, assim, produzir uma heterogeneidade de histórias. A disposição em contar as histórias de vida também foi levada em consideração no recrutamento para o estudo qualitativo. Tais entrevistas ocorreram em uma sala reservada na sede do PopTrans ou em outro lugar, de acordo com a indicação da própria participante.

Foram realizadas 19 entrevistas em profundidade ao longo do inquérito epidemiológico. As histórias de vida que emergiram do campo foram transcritas e analisadas sob uma perspectiva teóriconarrativa. Partiu-se do pressuposto de que uma narrativa é uma "forma de estabelecimento do sentido de ser-no-mundo, na medida em que situa os eventos e as ações em 'dramas' instituídos na ordem temporal do vivido", isto é, como "modos de elaboração da experiência social" 34 (p. 171).

As entrevistas em profundidade realizadas no campo foram orientadas por um roteiro prévio que explorou a produção de narrativas sobre as experiências e modos de vida das travestis e mulheres transexuais na cidade de Salvador. De forma dialógica, a entrevista foi tida como um "ato conversacional" e como espaço de "negociação" e de múltiplos posicionamentos e "vozes" 35, buscando mobilizar acontecimentos (e atores) diversos sobre o cotidiano. No que diz respeito à produção dessas narrativas, os/as entrevistadores/as buscavam focalizar os processos de construção de si e das modificações corporais, formas de interação com outras pessoas, os itinerários de cuidados com a saúde, incluindo as dificuldades e formas de acesso aos serviços de saúde, as formas de discriminação ou violência vividas no cotidiano e as expectativas e projetos para o futuro.

A postura analítica diante das narrativas foi inspirada pelo conceito de gênero cunhado por Butler 36 (p. 69), como uma "estilização repetida do corpo, um conjunto de atos repetidos no interior de uma estrutura reguladora altamente rígida, a qual se cristaliza no tempo para produzir a aparência de uma substância”. A ideia dessa autora sobre a performatividade do gênero pode ser traduzida como um prisma de deslocamentos, transgressões e fissuras que produz deslocamentos corporais, colocando em cheque a ideia do corpo como uma substância natural e pré-discursiva. Desse modo, a identidade de gênero que o corpo "quer" expressar por atos, gestos e atuações seria uma "fabricação" manufaturada e sustentada por meio de "signos corpóreos e outros meios discursivos" com o objetivo de regular a sexualidade através das regras da matriz heterossexual compulsória 36.

Também utilizamos o conceito goffmaniano de estigma como um atributo profundamente depreciativo identificado nas interações sociais 26 . Além disso, buscamos compreender os componentes do estigma nas narrativas: a simplificação das diferenças, associação das diferenças com características negativas e separação de sujeitos em grupos ${ }^{37}$. Levamos em consideração as principais repercussões do processo de estigmatização sobre a experiência de travestis e mulheres transexuais e os meios cotidianos de resistência ao estigma. Neste estudo, partiu-se do pressuposto de que a experiência e as práticas não podem ser dadas por fora do "eu", bem como o "eu" não pode ser separado do ambiente e das relações com outros seres.

Todas as participantes do estudo assinaram o Termo de Consentimento Livre e Esclarecido e foi garantido o anonimato e confidencialidade das entrevistas por meio da adoção de nomes fictícios. $\mathrm{O}$ projeto de pesquisa foi aprovado no Comitê de Ética em Pesquisa da Secretaria de Saúde do Estado da Bahia (no 225.943/2012).

\section{Resultados e discussão}

A sumarização de algumas características das travestis e mulheres transexuais entrevistadas foi organizada na Tabela 1. Trata-se de uma população diversa na composição etária (a idade variou de 19 a 54 anos), nas identidades (travesti, mulher, transexual), na escolaridade, cor de pele, renda, situação de trabalho e conjugal. O relato de discriminação, estupro e agressão foi reportado por muitas delas. 
Tabela 1

Características das travestis e mulheres transexuais do estudo. Salvador, Bahia, Brasil, 2014-2016.

\begin{tabular}{|c|c|c|}
\hline Variáveis & $\mathbf{n}$ & $\%$ \\
\hline \multicolumn{3}{|l|}{ Dados sociodemográficos } \\
\hline \multicolumn{3}{|l|}{ Idade (anos) } \\
\hline$<20$ & 3 & 15,8 \\
\hline $20-40$ & 12 & 63,2 \\
\hline$>40$ & 4 & 21,0 \\
\hline \multicolumn{3}{|l|}{ Anos de estudo } \\
\hline$\leq 8$ & 4 & 21,1 \\
\hline $8-12$ & 12 & 63,2 \\
\hline$\geq 12$ & 3 & 15,8 \\
\hline \multicolumn{3}{|l|}{ Cor de pele } \\
\hline Branca & 4 & 21,1 \\
\hline Preta & 3 & 15,8 \\
\hline Parda & 12 & 63,2 \\
\hline \multicolumn{3}{|l|}{ Renda (salário mínimo) } \\
\hline$\leq 1(\mathrm{R} \$ 740)$ & 5 & 26,3 \\
\hline $1-2$ & 6 & 31,6 \\
\hline$\geq 2$ & 8 & 42,1 \\
\hline \multicolumn{3}{|l|}{ Situação de trabalho } \\
\hline Emprego formal/informal/empresária & 4 & 21,1 \\
\hline Trabalho sexual & 15 & 78,9 \\
\hline \multicolumn{3}{|l|}{ Situação conjugal } \\
\hline Vive com companheiro/namorado & 4 & 21,1 \\
\hline Solteira & 14 & 73,7 \\
\hline Viúva & 1 & 5,3 \\
\hline \multicolumn{3}{|l|}{ Identidade de gênero } \\
\hline Transexual & 5 & 26,3 \\
\hline Travesti & 11 & 57,9 \\
\hline Mulher & 2 & 10,5 \\
\hline Outra & 1 & 5,3 \\
\hline \multicolumn{3}{|l|}{ História de discriminação } \\
\hline \multicolumn{3}{|l|}{ Ter sido forçada a fazer sexo } \\
\hline Não & 12 & 63,2 \\
\hline Sim & 7 & 36,8 \\
\hline \multicolumn{3}{|l|}{ Agressão pela polícia } \\
\hline Não & 11 & 57,9 \\
\hline Sim & 8 & 42,1 \\
\hline \multicolumn{3}{|l|}{ Discriminação na família } \\
\hline Não & 5 & 26,3 \\
\hline Sim & 10 & 52,6 \\
\hline Não respondeu & 4 & 21,1 \\
\hline \multicolumn{3}{|l|}{ Discriminação pelos vizinhos } \\
\hline Não & 3 & 15,8 \\
\hline $\operatorname{Sim}$ & 12 & 63,2 \\
\hline Não respondeu & 4 & 21,1 \\
\hline \multicolumn{3}{|l|}{ Agressão física } \\
\hline Não & 5 & 26,3 \\
\hline Sim & 14 & 73,7 \\
\hline \multicolumn{3}{|l|}{ Agressão verbal } \\
\hline Não & 4 & 21,1 \\
\hline Sim & 15 & 78,9 \\
\hline
\end{tabular}


A história de vida de muitas das travestis e mulheres transexuais parece indicar que a performance "afeminada" esteve presente nos corpos e nos objetos utilizados por elas desde a tenra infância, como marcas de separação das demais crianças, que coincide com outras histórias em outros estudos 8,20. Essa performance parece envolver dois elementos centrais: o corpo e os objetos, que interagem entre si e com as pessoas da interação social para retroalimentar um processo de rotulação.

O corpo é performado, ainda na infância e adolescência, por intermédio de trejeitos "de menina", "boiola", "viado", que são muitas vezes identificados por integrantes da família ou por pessoas próximas. Os objetos (boneca, toalha como cabelo, assessórios etc.) e roupas (vestidos, saias etc.) utilizados na infância possuem um agenciamento performático importante. Ambos são classificados como "coisa de mulher" e fazem parte da infância das travestis e mulheres transexuais, como se observa:

"Depois quando eu fui crescendo, já com 10 anos, todos já perceberam um jeito e aí já começou aquela história: 'esse menino é boiola" (Beatriz, 27 anos, mulher transexual, educadora social).

"E minha tia chegou um dia lá, viu uma boneca, eu brincando. Disse 'tá errado, homem brinca é de bola. Me dêessa boneca"' (Sofia, 50 anos, travesti, profissional do sexo).

"Eu lembro que meu pai falou comigo (...) que ele sempre soube, desde pequeno, que ele percebia que eu tinha trejeitos, que ele sempre soube" (Júlia, 28 anos, travesti, prostituta).

Observa-se que os objetos auxiliam a fabricação de uma performance "afeminada" e reafirmam a matriz heterossexual compulsória binária; possuindo, portanto, um agenciamento importante na ação humana 38 e em suas performances 39 . Além disso, são identificados como marcadores que distinguem a performance "afeminada" das travestis e mulheres transexuais daquelas apresentadas pelos meninos, frustrando a expectativa de muitos atores, a começar pelos membros da família.

Essas performances são vistas pelas pessoas que estão à sua volta, parafraseando Goffman 26 , como certo "atributo" depreciativo, ou mesmo como um "rótulo", o que para Link \& Phelan 37 expressaria melhor a ideia da construção social do estigma, tendo como foco principal o contexto e as pessoas que rotulam, ou seja, os aspectos estruturais que produzem o estigma, enquanto o "atributo" estaria mais relacionado ao indivíduo. As performances distinguem as travestis e mulheres transexuais de outras pessoas pelo processo de rotulação e de separação entre grupos considerados "normais" (ou aqueles tidos como apropriadamente generificados) e "anormais" (aqueles que não se encaixam na divisão binária). Esse atributo também parece impor a impossibilidade de atenção social para outros atributos e imputar sobre elas um grande descrédito. Assim, durante a infância, quase sempre essa performance provoca atos de discriminação e de violência contra as travestis e mulheres transexuais no ambiente da família, da escola e entre outras crianças, como relatados em outros estudos 8,28.

"Eu não falava muito, eu não interagia, não tinha amigo na escola, não tinha nada. Com seis, sete anos de idade, eu comecei a criar tudo isso, foi quando veio essa deficiência, minha timidez, insegurança. Sou muito insegura. Por causa das agressões da infância. (...) Eu apanhava, não sabia o que era (...) Eu dizia: 'por que eu estou apanhando?'. Eu lembro que na época ele [o irmão] dizia: 'Isso é coisa de mulher!'. Tudo que eu fazia era coisa de mulher" (Vanessa, 40 anos, travesti, faz shows e "programas").

O estigma existe quando os seguintes componentes inter-relacionados convergem: a simplificação das diferenças, associação das diferenças com características negativas e separação de sujeitos em grupos 37 . O primeiro deles se refere ao fato de que as pessoas distinguem e rotulam as diferenças humanas com uma substancial simplificação das diferenças, como se não houvesse uma gradação entre as diversas categorias. Nesse sentido, geralmente o dualismo entre as categorias prevalece: homem/mulher, gay/hétero, negro/branco etc., sem observar que os atributos considerados proeminentes diferem drasticamente de acordo com o tempo, lugar e padrão de classificação. Nesse ponto é importante observar que não existe consenso sobre o dualismo no gênero, nem mesmo na biologia, como demonstrado no ensaio de Fausto-Sterling 40 (p. 15): "o sexo de um corpo é simplesmente complexo demais. Não existe isso ou aquilo. Antes, existem nuances de diferença, (...) rotular alguém homem ou mulher é uma decisão social". Nesse sentido, ao contrariar o socialmente esperado, as nossas interlocutoras multiplicam as narrativas sobre discriminação sofrida ao longo de suas trajetórias de vida:

"Desisti de estudar pelos preconceitos. Eu pedia aos professores pra me chamar pelo nome feminino e eles me chamavam pelo masculino. Aí [os colegas] começavam a me jogar bolinha de papel..." (Manuela, 26 anos, mulher transexual, prostituta). 
O segundo componente do estigma envolveria a associação das diferenças humanas - que são rotuladas - com características negativas, a conexão entre essas duas propriedades conformaria o denominado de estereótipo. E o terceiro componente ocorreria quando os rótulos sociais promovem a separação entre duas categorias de pessoas: "nós" e "eles" 37. Neste estudo, não foram raras as narrativas sobre expulsão de travestis e mulheres transexuais de casa por conta da performance "afeminada”, que demonstram tanto a estereotipia, quanto a separação das travestis e mulheres transexuais do convívio familiar com aquelas pessoas consideradas apropriadamente generificadas, reforçando, portanto, um sistema de gênero binário oposicional, baseado na coerência sexo, gênero e desejo.

"Meu pai quando chegava às vezes e dizia: 'Não quero afeminado dentro de casa'. Ai eu já com 13, 14 anos. (...) Então, eu fugi com uma travesti pra o Rio de Janeiro" (Angélica, travesti, 26 anos, prostituta).

"Eu sempre fui afeminado desde criança e fui crescendo assim (...) quis sair da companhia da minha mãe, mas ela também mandava eu ir me embora. (...) Então, eu desde 14 anos que eu vivo só pelo mundo afora..." (Adélia, 61 anos, travesti, não tem ocupação no momento).

Lívia, por exemplo, cursou o Ensino Fundamental e sofreu muita discriminação em sua cidade de origem, uma pequena e pacata cidade do interior da Bahia, e da sua família. Ela compartilha que, apesar de tudo, ainda na infância em sua cidade, fazia pequenas modificações corporais e utilizava objetos femininos, como o "salto alto" e "roupas de mulher", na "Festa de Reis". Nessa comemoração, como em tantas outras festas baianas e brasileiras 41 , os meninos tinham o passe livre para assumir performances de gênero diferentes do normatizado. A festa popular foi narrada como momentos importantes em sua vida, pois lhe permitia o momento de felicidade em assumir a "verdade" feminina de sua pessoa:

"Fazia [modificações corporais] na festa de Reis, de Judas, que tem na cidade, onde os homens se vestiam de mulher (...) Ali era o melhor momento de minha vida, onde eu me sentia mais feliz, que eu botava aquele salto alto e pra mim ficava ótima. Ali era Lívia, ali era minha pessoa. Nasceu no corpo errado" (Lívia, 35 anos, mulher transexual, profissional do sexo).

Rubin 42 (p. 12) enfatiza que a "identidade de gênero exclusiva (...) requer repressão: nos homens, da versão local das características 'femininas'; nas mulheres, da definição local das características 'masculinas”. A autora completa que o "mesmo sistema social que oprime as mulheres nas suas relações de troca, oprime todo mundo pela sua insistência numa divisão rígida da personalidade" 42 (p. 12). Como descreve uma de nossas interlocutoras:

"Passei a apanhar muito mais ainda porque eu era pego também quando criança (...) brincando com meninos de ousadia, ai pegava me batia. Me pegavam brincando de boneca. Aí começou todos os maus tratos. Fui vestindo roupas femininas aos poucos e sofrendo, apanhando, deixava o cabelo crescer, meus tios pegava e cortava meus cabelos" (Beatriz, 27 anos, mulher transexual, educadora social).

Se, por um lado, existe um esforço em busca de uma performance diferente daquela que lhe foi imputada pela norma de gênero no nascimento, por outro lado, encontra-se também uma forte repressão dos familiares a todas características que fujam do padrão estabelecido. A construção do masculino heterossexual envolveria um complexo esforço de modelagem dos sujeitos que necessita do exorcismo de todas as características que fogem ao padrão estabelecido socialmente 43,44, denunciando, portanto, a fragilidade da naturalização dessas identidades, e fortalecendo a tese de construção social das categorias sexo e gênero 36.

\section{"Vou embora pra Salvador": trajetórias de vida e interações sociais}

Yasmin (mulher transexual e cabelereira), uma garota de 21 anos, proveniente de uma cidade interiorana, relata que sua performance "afeminada" começou a ser identificada pelas outras pessoas ainda na infância: "eu era uma criança muito afeminada. Todos falavam". A sua infância com a família, diferentemente das outras travestis e mulheres transexuais, foi considerada por ela como "maravilhosa”. Apesar do esforço do entrevistador questionar repetidamente sobre a discriminação na infância, Yasmin repetidamente respondeu: "minha infância foi maravilhosa, com a família. Minha família era sempre maravilhosa. (...) Todo mundo na minha família é muito unida. Primo, tio, todo mundo. Minha família se relaciona muito bem".

Entretanto, a partir da sua adolescência, especificamente aos 15 anos, passou a vivenciar problemas com sua mãe. Nesse período, logo após a morte da avó, sua mãe recorreu ao apoio psicológico 
para ajudá-la a mudar seus comportamentos. Nesse ínterim, a nossa interlocutora começa a tomar comprimidos de hormônios femininos, obtidos por meio de amigas e conforme informações provenientes de outras travestis e mulheres transexuais da sua cidade. Começou a vestir roupas femininas, também ofertadas por amigas. E, ao completar 18 anos, embarcou para Salvador na tentativa de tentar sua independência financeira e realizar sua modificação corporal: "colocar minha prótese" e o "silicone industrial".

Pelúcio 11,12 destaca que a construção de uma travesti é um processo contínuo e que nunca termina, pois está calcado na construção permanente de uma performance feminina com o auxílio de hormônios, injeções de silicone, roupas e acessórios. Todavia, a ausência de acesso a hormônios 13,20 e tecnologias cirúrgicas para modificação corporal 25 para as travestis e mulheres transexuais impactou de forma importante a trajetória de vida de Yasmin. Assim, para atingir seu objetivo de transformação corporal, tal como muitas outras, ao chegar à capital baiana, foi morar com amigas travestis e mulheres transexuais, fazendo programa no bairro da Pituba, orla de Salvador, um dos circuitos importantes de interação e trabalho sexual.

Beatriz também foi trabalhar neste mesmo local por conta da ausência de oportunidades no mercado de trabalho formal. Esse fenômeno, como destaca nossa interlocutora, foi consequência da discriminação por conta da sua performance de gênero no trabalho:

"Fui trabalhar numa empresa de RH. Era promotora de vendas externas da Credicard. Mas eu sofria preconceito dos clientes, o povo perguntava: que é isso? Um menino ou uma mulher? Eu saí logo em seguida porque não conseguia me vestir de homem. É como uma mulher CIS se vestisse de homem. Depois trabalhei como operadora de telemarketing. Mas lá entrei de homem. (...) observei que quando eu ia de mulher, não passava, $e$ de homem eu passava" (Beatriz, 23 anos, mulher transexual, educadora social).

Outros estudos também indicam que o estigma relacionado à identidade de gênero pode ser uma barreira importante para o acesso das mulheres transgêneras à escolaridade 15,27,28 e ao emprego formal 20,27,28, que as direciona muitas vezes a uma situação de marginalização socioeconômica 24,45, e que geralmente justifica sua entrada no trabalho sexual 20,27,28. O trabalho sexual muitas vezes é realizado por conta dos parcos recursos financeiros, necessidade e falta de opções laborais, também é geralmente feito em condições precárias de segurança e expostas a uma diversidade de riscos (sexuais, abusos, roubos etc.) 28 , como narrado pela própria Beatriz:

"Fui estuprada na Pituba. Fui obrigada a fazer sexo com usuário de droga. O cara veio por de trás, colocou uma faquinha no meu pescoço e disse: 'Vumbora, eu vou enfiar no seu pescoço, nem corra, sua desgraça.... E aí eu desci para areia da praia, mandou eu baixar e me comeu. Gozou dentro de mim. (...). Com risco de pegar HIV, sexo com a arma a minha cabeça" (Beatriz, 23 anos, mulher transexual, educadora social).

O estudo etnográfico realizado por Pelúcio 11,12 mostrou que a prostituição é uma "atividade desprestigiosa", na visão de muitas travestis, e motivada pela "necessidade" de recursos financeiros. Contudo, o trabalho sexual não foi o destino de todas as travestis e mulheres transexuais do nosso estudo. Renata, que apesar de ter sofrido também discriminação de alguns atores (cunhados, irmão), narra uma história de acolhimento emocional e financeiro pelos pais, mesmo depois da sua transformação corporal, que foi fundamental para sua não entrada nesse mercado:

"Não [me prostituía] porque não tinha necessidade. (...) Eu tenho hormônio, tenho o que comer. Meu pai sempre me dava dinheiro final de semana. Quando eu não tinha pedia a minha mãe, minha mãe me dava" (Renata, 31 anos, transexual, servidora pública).

A história narrada por Lívia também mostra personagens que a acolheram durante seu processo de modificação corporal. Enquanto sua mãe foi narrada como uma personagem que não a aceitava, a sua tia foi tida como a pessoa que abriu caminhos para sua modificação corporal ao acolhê-la em seu lar na cidade de Salvador: "quando ela [minha mãe] disse 'Seu viado', eu disse (...) 'sou mesmo'. (...) E disse 'eu vou embora, (...) eu vou embora pra Salvador'. E minha tia disse 'se você quiser, eu te levo"'. Na casa da sua tia, numa cidade grande, Lívia encontrou um ambiente favorável à sua modificação corporal e foi até mesmo incentivada: "foi meu aniversário. [Minha tia] Comprou e me deu (...) três calcinhas (...). Estava com 18 pra 19 anos". 
A violência física e o assassinato de travestis e mulheres transexuais também foram relatados no nosso estudo. Benedetti 46, com base em etnografia com travestis no Sul do Brasil, chama a atenção também para a violência. $\mathrm{O}$ autor chega a relatar que quatro informantes foram assassinadas durante o seu trabalho de campo, evento narrado como mortes extremamente "violentas e mesmo aterrorizantes".

Neste estudo, a narrativa mais marcante foi de Lucília (49 anos, mulher transexual, cozinheira), que nos contou a história de uma transformista muito conhecida: Laleska D’Capri. Ela argumenta que se Laleska estivesse viva, certamente se autoidentificaria como uma mulher transexual, pois naquela época não havia diferenças muito claras entre as categorias "travesti”, "transexual" e "transformista" indicando como essas categorias são fluidas e construídas socialmente:

"Ela era ator transformista, ela, com certeza, se tivesse viva hoje, seria uma transexual. Porque ela tinha trejeitos, da mesma forma usava roupas, oscilava entre o masculino e o feminino. (...) Seria uma trans porque hoje não é o tempo de antigamente. (...) Era um espaço na Amaralina, onde todas se reuniam, pra dá uma churria uma na outra. (...) Houve uma discussão com um homofóbico. E que nessa situação ele saiu e, quando voltou, voltou armado e disparou três tiros nela. (...) Ela morreu na posição de Cristo. (...) Lembro da posição dela com as duas pernas cruzadas, com mãos abertas, os braços abertos e com a mão fechada".

A história do assassinato narrado por Lucília é um ponto de inflexão na narrativa da violência gerada pelo estigma. Foucault 47 (p. 91) postula que "onde há poder há resistência e, no entanto (ou melhor, por isso mesmo) esta nunca se encontra em posição de exterioridade em relação ao poder". Levando em consideração a ideia desse autor, poder-se-ia dizer que na experiência do estigma (que é permeada por intensas relações de poder entre indivíduos, famílias, desconhecidos, instituições etc.), sempre existe possibilidade de resistência, que é coexistente ao poder. É isso que também podemos identificar na narrativa de Lucília, que entende que, para permanecer no mundo, deverá seguir certo "caminho". O ponto culminante da narrativa é a criação de uma associação de defesa dos direitos humanos de travestis e mulheres transexuais na cidade de Salvador, como se pode observar a seguir:

"Ela morreu, claro, muito mais por ser um trans. Se fosse uma mulher, jamais seria assassinada (...) A partir desse momento alguns amigos em comum, gays e algumas trans, resolveram fundar uma associação chamada 'Laleska D'Capri', que era o nome dela de show, de artista transformista, e nós resolvemos montar uma associação justamente pra visibilizar (...). E aí, a partir daí, fui convidada a fazer parte do Fórum LGBT Baiano. E no primeiro ano de existência, nós saímos enquanto Colegiado, a Laleska D’Capri saiu como Colegiado".

Outras travestis e mulheres transexuais também compartilharam histórias de resistência no cotidiano das interações sociais. Lívia, por exemplo, embora tenha sofrido discriminação, não absorveu tais atos de forma passiva, e relata o seu envolvimento no movimento social em defesa dos direitos LGBT, recrutando outras parceiras: "os que não era, eu fiz virar [militante]. (...) E depois comecei a botar na cabeça 'olha, bicha, tá vendo essa lei que saiu?'. Foi com muito trabalho de todas nós junto".

Em outros locais também podemos identificar movimentos sociais e grupos de apoio às travestis e mulheres transexuais, por exemplo, no Brasil 8, no Líbano 27 e na Índia 21. Desse modo, verifica-se que as travestis e mulheres transexuais não estão fadadas passivamente à estigmatização, mas que muitas conseguem se organizar em coletivos, ou até mesmo lutar no cotidiano diário contra o estigma na escola, no trabalho e nos espaços da vida cotidiana, mostrando que o processo de estigmatização possui fissuras que permitem a movimentação de sujeitos mediante resistência, como se pode constatar:

"Eu fiz vestibular e passei, né? (...) entendo de que hoje sou um ativista social também, que tenho que lutar por um espaço meu (...) passei numa seleção" (Beatriz, 27 anos, educadora social).

"Hoje eu faço questão de mostrar a meu pai e minha mãe, os jornais e as entrevistas, porque hoje em dia eu sou alguém. 'Aqui óh, estou dando exemplo para vocês. Não é o que vocês pensavam o que eu ia ser"' (31 anos, transexual, servidora pública).

Foucault 48 destaca que as relações de poder são produtivas, e sempre que há uma relação de poder, existe uma possibilidade de resistência. Essa resistência é exatamente como o poder, "tão inventiva, tão móvel, tão produtiva quanto ele" 48 (p. 360), vem de baixo e se distribui estrategicamente. O movimento de resistência foi observado por conta da construção de organizações sociais de luta contra a discriminação, da afirmação da identidade trans nos espaços cotidianos pela performance de seus próprios corpos ou mesmo pela conquista de novos espaços sociais (ex.: faculdade, trabalho, mudança de cidade). 
As travestis e mulheres transexuais, por questionarem corporalmente e performaticamente as fronteiras de gênero impostas, colocam em cheque a categoria "sexo", dada naturalmente como o real, e mostra em seus próprios corpos como esta categoria é "um ato de dominação e coerção, um ato performativo institucionalizado que cria e legisla a realidade social pela exigência de uma construção discursiva/ perceptiva dos corpos" 36 (p. 200). É nesse ponto que a abjeção pode ser encarada não apenas como uma sujeição passiva, mas como uma manifestação clara de possibilidades de empoderamento e de resistência ao poder heteronormativo, pois denuncia a "essencialidade" da categoria sexo.

\section{Considerações finais}

As performances de gênero de nossas interlocutoras neste estudo são apresentadas como uma verdadeira insubordinação ao poder estabelecido pela sociedade heteronormativa. Pode-se notar também que o processo de estigmatização é operado por meio do poder exercido pelas leis da heterossexualidade compulsória sobre os corpos e relações sociais de travestis e mulheres transexuais. Viu-se que, quando as expectativas sociais (heteronormativas) são frustradas, o processo de estigmatização opera por intermédio da identificação de rótulos depreciativos, que são identificados neste estudo como as performances de gênero não normativas.

Pelas experiências de travestis e mulheres transexuais, observou-se o caráter relacional do estigma, como defendido por Goffman 26, ao argumentar que um atributo em si mesmo não é nem honroso nem desonroso, pois ele só é percebido como tal nas relações interpessoais, por exemplo, nas interações com a família, professores, amigos, vizinhos e outros sujeitos. Pode-se notar, também, diversas fissuras que o estigma pode sofrer pela resistência das (trans) experiências.

Butler 36 aponta que o sexo cravado nos corpos humanos é um dispositivo discursivo através do qual a norma estável binária (homem versus mulher) estaria resguardada. Por este estudo, vê-se que as travestis e mulheres transexuais borram ou confundem no próprio corpo a separação heteronormativa entre gênero e sexo ${ }^{1}$, visto que mostram que o sexo "natural" pode ser tão construído culturalmente quanto o gênero.

Este estudo aponta também para a necessidade de novas investigações que possam discutir e problematizar algumas das tensões e deslocamentos identitários, movimentos de resistência ao processo de estigmatização, sobretudo aqueles que estão ocorrendo no cotidiano das intersubjetividades, considerando os aspectos da violência, discriminação e patologização das identidades subversivas às normatizações de gênero.

\section{Colaboradores}

L. Magno participou do trabalho de campo, concepção do artigo, escrita e revisão final do manuscrito. I. Dourado e L. A. V. Silva coordenaram a pesquisa, participaram da concepção da pesquisa, do trabalho de campo e da revisão final do manuscrito.

\section{Agradecimentos}

Os autores agradecem à ATRAS/Millena Passos; à IBCM/Padre Alfredo Dorea; à Keila Simpson e a Ailton Santos pelo incentivo com o tema; à Lucília Nascimento pela coordenação de campo; ao Departamento Nacional de IST, AIDS e Hepatites Virais/Ministério da Saúde. Projeto aprovado pelo Comitê de Ética e Pesquisa da Secretaria de Saúde do Estado da Bahia. Parecer 225.943, CAAE: 07135912.7.0000.0052. 


\section{Referências}

1. Butler J. Corpos que pesam: sobre os limites discursivos do sexo. In: Louro GL, organizador. O corpo educado. 2a Ed. Belo Horizonte: Autêntica Editora; 2000. p. 151-68.

2. Miskolci R. A Teoria Queer e a sociologia: o desafio de uma analítica da normalização. Sociologias 2009; (21):150-82.

3. Lionço T. Atenção integral à saúde e diversidade sexual no processo transexualizador do SUS: avanços, impasses, desafios. Physis (Rio J.) 2009; 19:43-63.

4. Arán M, Murta D. Do diagnóstico de transtorno de identidade de gênero às redescrições da experiência da transexualidade: uma reflexão sobre gênero, tecnologia e saúde. Physis (Rio J.) 2009; 19:15-41.

5. Dourado I, Silva LAV, Magno L, Lopes M, Cerqueira C, Prates A, et al. Building bridges: interdisciplinarity in practice. PopTrans Study: a study with transvestites and transsexual women in Salvador, Bahia State, Brazil. Cad Saúde Pública 2016; 32:e00180415.

6. White Hughto JM, Reisner SL, Pachankis JE. Transgender stigma and health: a critical review of stigma determinants, mechanisms, and interventions. Soc Sci Med 2015; 147:222-31.

7. Association American Psychiatric. Diagnostic and statistical manual of mental disorders (DSM-5). Washington DC/London: Amerian Psychiatric Publishing; 2013.

8. Andrade LN. Travestis na escola: assujeitamento e resistência à ordem normativa [Tese de Doutorado]. Fortaleza: Programa de Pósgraduação em Educação, Faculdade de Educação, Universidade Federal do Ceará; 2012.

9. Bento B. A reinvenção do corpo: sexualidade e gênero na experiencia transexual. Rio de Janeiro: Editora Garamond; 2006.

10. Carrara S, Vianna ARB. Lethal violence against travestis in Rio de Janeiro city based. Physis (Rio J.) 2006; 16:233-49.

11. Pelúcio L. Na noite nem todos os gatos são pardos: notas sobre a prostituição travesti. Cadernos Pagu 2005; (25):217-48.

12. Pelúcio L. "Toda quebrada na plástica”: corporalidade e construção de gênero entre travestis paulistas. Revista de Antropologia Cultural 2005; 6:97-112.

13. Palazzolo SL, Yamanis TJ, De Jesus M, Maguire-Marshall M, Barker SL. Documentation status as a contextual determinant of HIV risk among young transgender Latinas. LGBT Health 2016; 3:132-8.
14. Melendez RM, Pinto R. "It's really a hard life": love, gender and HIV risk among male-to- female transgender persons. Cult Health Sex 2007; 9:233-45.

15. Cuadra-Hernández SM, Zarco-Mera A, Infante-Xibillé C, Caballero-García M. La organización de las poblaciones clave ligadas a la transmisión del VIH: una intervención para abatir el estigma; México, 2005-2009. Salud Colect 2012; 8:191-204.

16. Stahlman S, Liestman B, Ketende S, Kouanda $\mathrm{S}$, Ky-Zerbo O, Lougue M, et al. Characterizing the HIV risks and potential pathways to HIV infection among transgender women in Cote d'Ivoire, Togo and Burkina Faso. J Int AIDS Soc 2016; 19(3 Suppl 2):20774.

17. Infante C, Sosa-Rubi SG, Cuadra SM. Sex work in Mexico: vulnerability of male, travesti, transgender and transsexual sex workers. Cult Health Sex 2009; 11:125-37.

18. Kulick D. Travesti: sex, gender and culture among Brazilian transgendered prostitutes. Chicago: University of Chicago Press; 1998.

19. Kaplan RL, McGowan J, Wagner GJ. HIV prevalence and demographic determinants of condomless receptive anal intercourse among trans feminine individuals in Beirut, Lebanon. J Int AIDS Soc 2016; 19(3 Suppl 2):20787.

20. Gibson BA, Brown S-E, Rutledge R, Wickersham JA, Kamarulzaman A, Altice FL. Gender identity, healthcare access, and risk reduction among Malaysia's mak nyah community. Glob Public Health 2016; 11:1010-25.

21. Ganju D, Saggurti N. Stigma, violence and HIV vulnerability among transgender persons in sex work in Maharashtra, India. Cult Health Sex 2017; 19:903-17.

22. Alencar Albuquerque G, de Lima Garcia C, da Silva Quirino G, Alves MJ, Belém JM, dos Santos Figueiredo FW, et al. Access to health services by lesbian, gay, bisexual, and transgender persons: systematic literature review. BMC Int Health Hum Rights 2016; 16:2.

23. Cerqueira-Santos E, Calvetti PU, Rocha KB, Moura A, Barbosa LH, Hermel J. Percepção de usuários gays, lésbicas, bissexuais e transgêneros, transexuais e travestis do Sistema Único de Saúde. Interam J Psychol 2010; 44:235-45.

24. Barrington C, Knudston K, Alicia O, Bailey P, Aguilar JM, Loya-Montiel MI, et al. HIV diagnosis, linkage to care, and retention among men who have sex with men and transgender women in Guatemala city. J Health Care Poor Underserved 2016; 27:1745-60. 
25. Estrada-Montoya JH, García-Becerra A. Reconfiguraciones de género y vulnerabilidad al VIH/Sida en mujeres transgénero en Colombia. Rev Gerenc Políticas Salud 2010; 9:90102.

26. Goffman E. Estigma: notas sobre a manipulação da identidade manipulada. Rio de Janeiro: LTC; 2013.

27. Kaplan RL, Wagner GJ, Nehme S, Aunon F, Khouri D, Mokhbat J. Forms of safety and their impact on health: an exploration of hiv/ aids-related risk and resilience among trans women in Lebanon. Health Care Women Int 2015; 36:917-35.

28. Boivin RR. "Se podrían evitar muchas muertas": discriminación, estigma y violencia contra minorías sexuales en México. Sex, Salud Soc (Rio J.) 2014; (16):86-120.

29. Giami A, Le Bail J. HIV infection and STI in the trans population: a critical review. Rev Epidemiol Sante Publique 2011; 59:259-68.

30. DiStefano AS. HIV's syndemic links with mental health, substance use, and violence in an environment of stigma and disparities in Japan. Qual Health Res 2016; 26:877-94.

31. Sevelius JM, Patouhas E, Keatley JG, Mallory OJ. Barriers and facilitators to engagement and retention in care among transgender women living with human immunodeficiency virus. Ann Behav Med 2014; 47:5-16.

32. Logie $\mathrm{CH}$, Lacombe-duncan A, Wang Y, Jones N, Levermore K, Neil A, et al. Prevalence and correlates of HIV infection and HIV testing among transgender women in jamaica. AIDS Patient Care STDS 2016; 30:416-24.

33. Almeida-Filho N, Fernandes R, Larrea-Killinger C, Silva L. Construindo a etnoepidemiologia. In: Almeida Filho N, Barreto M, organizadores. Epidemiologia \& saúde: fundamentos, métodos, aplicações. Rio de Janeiro: Editora Guanabara Koogan; 2011. p. 386-95.

34. Castellanos MEP. A narrativa nas pesquisas qualitativas em saúde. Ciênc Saúde Coletiva 2014; 19:1065-76.
35. Silva LAV. Saúde e produção de sentidos no cotidiano: práticas de mediação e translinguística bakhtiniana. Interface Comun Saúde Educ 2003; 7:135-46.

36. Butler J. Problemas de gênero: feminismo e subversão da identidade. Rio de Janeiro: Civilização Brasileira; 2016.

37. Link BG, Phelan JC. Conceptualizing stigma. Annu Rev Sociol 2001; 27:363-85.

38. Latour B. Os objetos têm história? Encontro de Pasteur com Whitehead num banho de ácido láctico. Hist Ciênc Saúde-Manguinhos 1995; 2:7-26.

39. Race K. Framing responsibility: HIV, Biomedical prevention, and the performativity of the law. J Bioeth Inq 2012; 9:327-38.

40. Fausto-Sterling A. Dualismos em duelo. Cadernos Pagu 2002; (17-18):9-79.

41. Damatta R. A casa \& a rua: espaço, cidadania, mulher e morte no Brasil. 5a Ed. Rio de Janeiro: Editora Rocco; 1997.

42. Rubin G. O tráfico das mulheres: notas sobre a "economia política” do sexo. Recife: S.O.S Corpo; 1993

43. Bourdieu P. A dominação masculina. Rio de Janeiro: Bertrand Brasil; 2005.

44. Connel RW, Lecture C. Understanding men: gender sociology and the new. Social Thought \& Research 2002; 34:13-31.

45. Salazar LF, Crosby RA, Jones J, Kota K, Hill B, Masyn KE. Contextual, experiential , and behavioral risk factors associated with HIV status: a descriptive analysis of transgender women residing in Atlanta, Georgia. Int J STD AIDS 2017; 28:1059-66.

46. Benedetti MR. Toda feita: o corpo e o gênero das travestis. Rio de Janeiro: Editora Garamond; 2005.

47. Foucault M. A história da sexualidade I: a vontade de saber. 3a Ed. Rio de Janeiro: Edições Graal; 1977.

48. Foucault M. A microfísica do poder. 26a Ed. São Paulo: Edições Graal; 2013. 


\section{Abstract}

This was a qualitative study based on an analysis of narratives produced by travestis and transsexual women in Salvador, Bahia State, Brazil, with the aim of analyzing their experiences with stigmatization by describing events, actors, and contexts that have marked their life stories, as well as elucidating the relationship between stigma and their female performances. The narratives came from 19 in-depth interviews during an epidemiological survey, based on a prior script that explored the production of narratives on lifestyles and experiences of travestis and transsexual women in the city of Salvador. The life stories that emerged in the field were transcribed and analyzed from a theoretical and narrative perspective. The narratives of many travestis and transsexual women described an "effeminate" gender performance that had been identified since their childhood by family and community members. This performance was presented as insubordination to the power established by heteronormative society's legal system. The process of stigmatization begins to operate when social expectations concerning the coherence between "biological sex" and "gender performance" are frustrated in social interactions, submitting the individuals to discrimination and violence. Thus, stigmatization is operated through the power exercised over bodies by the laws of compulsory heterosexuality. However, during the life stories of travestis and transsexual women, strategies of resistance to stigma are produced, with the potential to transform this situation.

Exposure to Violence; Social Stigma; Gender Identity; Transgender Persons

\section{Resumen}

Se trata de un estudio cualitativo, en base al análisis de relatos elaborados por travestis y mujeres transexuales en Salvador, Bahia, Brasil, con el objetivo de analizar sus experiencias de estigmatización, describiendo acontecimientos, actores y contextos que marcan sus trayectorias de vida, $y$ también comprender la relación entre el estigma y sus performances femeninas. Los relatos provienen de diecinueve entrevistas en profundidad, realizadas a lo largo de una investigación epidemiológica. Al grupo objetivo se le orientó mediante un guion previo, que exploró la producción de relatos sobre experiencias y modos de vida de las travestis y mujeres transexuales en la ciudad de Salvador. Las historias de vida que emergieron del trabajo de campo fueron transcritas y analizadas bajo una perspectiva teórico-narrativa. Se observó que muchas travestis y mujeres transexuales presentaron en sus relatos la descripción de una performance de género "afeminada", que es identificada desde la infancia por miembros de la familia y de la comunidad. Esta performance se presenta como una insubordinación al poder establecido por el sistema jurídico de una sociedad heteronormativa. El proceso de estigmatización comienza a funcionar cuando las expectativas sociales sobre la coherencia entre "sexo biológico" y "performance de género" se frustran en las interacciones sociales, sometiendo a las personas a discriminación y violencia. De este modo, el proceso de estigmatización es sufrido a través del poder ejercido por las leyes de la heterosexualidad obligatoria sobre el concepto de cuerpo. No obstante, en el trascurso de las trayectorias de vida de las travestis y mujeres transexuales, se produjeron estrategias de resistencia contra el estigma con una potencial de transformación de los marcos establecidos.

Exposición a la Violencia; Estigma Social; Identidad de Género; Personas Transgénero
Recebido em 07/Ago/2017

Versão final reapresentada em 21/Nov/2017 Aprovado em 07/Dez/2017 